\title{
Effect of Pre-treatments in the Processing of Pineapple Leaf Fibers
}

\author{
Jean Rome Malou ${ }^{1}$, Walter Tita ${ }^{1}$, Johan Perret ${ }^{1}$, Ashutosh Singh ${ }^{2}$, Roger Moya Roque ${ }^{3}$, Gopu \\ Raveendran Nair ${ }^{1}$ \\ ${ }^{1}$ Earth University, Guapiles, Costa Rica, \\ ${ }^{2}$ School of Engineering, University of Guelph, Ontario, Canada, \\ ${ }^{3}$ Costa Rican Institute of Technology, Cartago, Costa Rica \\ Email: gnair@earth.ac.cr
}

\begin{abstract}
Hot water and alkali treatments were performed on pineapple leaves at three different temperatures $\left(50^{\circ} \mathrm{C}, 70^{\circ} \mathrm{C}\right.$ and $\left.90^{\circ} \mathrm{C}\right)$ and three different levels of concentrations of $\mathrm{NaOH}$ solution $(2$, 4 , and $6 \%$ ). The effect of pre-treatment was analyzed by comparing the physical qualities of pineapple leaf fiber (PALF). A physical property analysis of the PALF extracted after two pretreatments was carried out by measuring tensile strength, percentage of elongation, color, and surface properties of PALF. The PALF pre-treated at $70^{\circ} \mathrm{C}$ for $15 \mathrm{~min}$ showed maximum average tensile strength of $1206.3 \pm 753.02 \mathrm{MPa}$ and the lowest value of $353.1 \pm 41.51 \mathrm{MPa}$ were recorded for PALF pre-treated at $90{ }^{\circ} \mathrm{C}$ for $45 \mathrm{~min}$. In alkali pre-treated PALF, the maximum tensile strength of 1137.2 $\pm 28.01 \mathrm{MPa}$ was recorded for pineapple leaves treated with $2 \% \mathrm{NaOH}$ for $6 \mathrm{~h}$. In both hot water and alkali treated PALF, the percentage elongation was lower compared to the non-treated PALF. Hot water treated PALF recorded higher percentage of elongation than Alkali treated PALF. The tensile strength and percentage elongation in both treatments showed similar increase with respect to an increase in temperature and alkalinity. PALF treated with hot water showed more color change than Alkali treated PALF. The hot water treated PALF registered a maximum color change $(\Delta \mathrm{E})$ of $23.692\left(70{ }^{\circ} \mathrm{C}-45 \mathrm{~min}\right)$ while the alkali treated PALF showed a maximum color change $(\Delta \mathrm{E})$ of $19.721(6 \%-2 \mathrm{~h})$. However, the latter showed better surface properties than hot water treated PALF.
\end{abstract}

Keywords: Pineapple leaf, natural fiber, extraction

\section{Introduction}

Pineapple (Ananas comosus) is one of the major tropical fruit plants widely grown around the world [1]. According to FAOSTAT, in 2013 production of pineapple fruit was 24.8 million tons globally, where Costa Rica as the largest producer followed by Philippines, Brazil, Thailand, and India (FAOSTAT, 2013). Pineapple leaf fiber is one by-product from pineapple plant that has tremendous potential to be used in the biocomposite industry because of its biodegradability and strength $[2,3]$. Biofibers are widely used in automobile industry, building construction, partition wall cabinets, paper industry, apparel industry and in making of fiber reinforced composites [4]. For instance, in India pineapple is produced in approximately 872000 hectares of land and from this around 600000 tons of PALF can be extracted after the harvesting of pineapple [5].

Pineapple leaf contains around 2.5-3.5\% natural fiber, covered by a hydrophobic waxy layer beneath the outer layer. The PALF contains holocellulose and alpha-cellulose in major quantities, hemicellulose and lignin in small quantities [6, 7]. It is a smooth white colored glossy long fiber with high tensile strength [8]. With millions of tons of pineapple leaves discarded yearly, thousands of tons of natural fiber could be extracted and be able to industrialize and commercialize the processing of PALF. The growth of biocomposite industry would improve the possibilities to minimize the wastage of pineapple leaves as a potential source of natural fiber $[9,10]$. PALF also shows high specific strength and stiffness, which is hydrophilic because of its high cellulose content $[11,12,13]$.

Conventional extraction of PALF is performed by scrapping method using roller type scrapers. Usually PALF scrapping machine consists of 3 rollers such as i) feed rollers, ii) leaf scratching rollers, and iii) serrated rollers. Pineapple leaves are fed into the machine using the feed roller, and then the 
waxy layer is removed by the scratching roller. The serrated roller then breaks the leaves for fiber extraction [5, 14]. The mechanical extraction process is followed by pre-treatment of crushed pineapple leaves (retting), which is usually conducted either by chemical method (chemical retting) or by immersing it in water for longer duration (water retting).

Experiments were conducted at EARTH University, in order to develop a new pre- treatment method for the processing of pineapple leaves in to natural fiber by adopting hot water treatment, and to compare this method with alkali treatment. The objective of this research was to investigate the effect of short duration hot water pre-treatment on crushed pineapple leaves and to compare this process with alkali treated pineapple leaves by analyzing the physical properties of PALF.

\section{$2 \quad$ Materials and Methods}

\subsection{Pineapple Leaves}

The pineapple leaves were collected from plants of MD2 variety grown in the farm of EARTH University. The initial moisture content of the leaves was found to be $47.03 \%$ (wet basis) by oven drying method [7]. The leaves were cut into pieces of $0.15 \mathrm{~m}$ length and crushed before subjected to pretreatment. All the experiments were conducted using the middle portion of pineapple leaves in order to ensure uniformity.

\subsection{Pre- Treatments of Pineapple Leaves}

The crushed pineapple leaves $(0.15 \mathrm{~m})$ were subjected to hot water and alkali pre- treatment before the separation of the fiber.

\subsubsection{Hot Water Treatment}

Pre- treatments were conducted by boiling the pineapple leaves at different temperatures $(50,70$, and $90^{\circ} \mathrm{C}$ ) at different time intervals $(15,30$, and $45 \mathrm{~min})$. Then the pineapple leaves were oven- dried at $60^{\circ}$ $\mathrm{C}$ for $24 \mathrm{~h}$ and fibers were decorticated. The separated fibers were then subjected to evaluation of its physical properties.

\subsubsection{Alkali Treatment}

Pineapple leaves were immersed in alkali $(\mathrm{NaOH})$ solutions at 3 levels of concentrations $(2,4$, and $6 \%$ $\mathrm{w} / \mathrm{w})$ and 3 levels of treatment time $(2,4$, and $6 \mathrm{~h})$. The leaves were oven dried at $60^{\circ} \mathrm{C}$ for $24 \mathrm{~h}$ and then the fibers were separated. Later, the physical properties of these fibers were evaluated.

\subsection{Measurement of Physical Properties}

\subsubsection{Tensile Strength and Elongation}

The pineapple leaf fibers samples were randomly selected from the decorticated fibers and samples were tested three times (ASTM D3822-07). The tensile strength test was performed with a gauge length of $100 \mathrm{~mm}$. The fiber was mounted on the tensile test machine (Tinius Olsen H10T, Tinius Olsen TMC, United States) the top end being attached to the machine with a high-grip clip and the other end was connected to the bottom grip. After the fiber was mounted on the machine, top head moved at a speed of $10 \mathrm{~mm}$ per minute until the fiber broke into two pieces and the force, elongation and displacement were recorded $[7,15]$.

\subsubsection{Color Analysis}

The normal color of PALF is cream to light brown which varies with the variety and the treatments involve in the fiber processing. Since the processing of PALF consists of heat involved treatments, it is appropriate to have minimum changes in the color after these treatments. Changes in the color of PALF after hot water /alkali treatments with respect to non- treated PALF (control) were analyzed to find out if there were any significant color changes in its color with respect to the hot water/alkali treatments. The color of PALF was measured with the CIE $1976 \mathrm{~L}^{*}, \mathrm{a}^{*}, \mathrm{~b}^{*}$ color space (CIE, 2007) by a tristimulus colorimeter (Minolta Co. Ltd., Japan). According to CIE color space, L* represents whiteness (brightness)/darkness, $\mathrm{a}^{*}$ represents redness/greenness and $\mathrm{b}^{*}$ represents yellowness/blueness. The color difference was measured by the following method: PALF samples were placed on a white surface and the $\mathrm{L}^{*}, \mathrm{a}^{*}, \mathrm{~b}^{*}$ values were measured and the process was repeated 3 times. Color difference 
values $\Delta \mathrm{L}^{*}, \Delta \mathrm{a}^{*}$ and $\Delta \mathrm{b}^{*}$ were determined by subtracting the measured values $\mathrm{L}^{*}, \mathrm{a}^{*}, \mathrm{~b}^{*}$ of the treated PALF from the $\mathrm{L}^{*}, \mathrm{a}^{*}, \mathrm{~b}^{*}$ values of control sample [7]. The total color difference $\Delta \mathrm{E}$ is measured as (Minolta, 1991)

$$
\Delta E=\sqrt{\Delta \mathrm{L}^{* 2}+\left(\Delta \mathrm{a}^{*}\right)^{2}+\left(\Delta \mathrm{b}^{*}\right)^{2}}
$$

\subsubsection{Analysis of Surface Properties}

Analysis of surface roughness/cleanliness was carried out by obtaining pictures of surface by an optical microscope (specify make and model) equipped with a digital camera of scale (1: 100).

\section{$3 \quad$ Results and Discussion}

\subsection{Tensile Strength and Elongation \\ 3.1.1 Tensile Strength}

The average tensile strength of pineapple leaf fiber ranges between 350-700 $\mathrm{MPa}$ [16]. The tensile strength of hot water treated pineapple leaf fibers is as shown in Figure 1. As per Figure 1, the PALF treated at $70^{\circ} \mathrm{C}$ for 15 min showed maximum average tensile strength of $1206.3 \pm 75.3 .02 \mathrm{MPa}$.

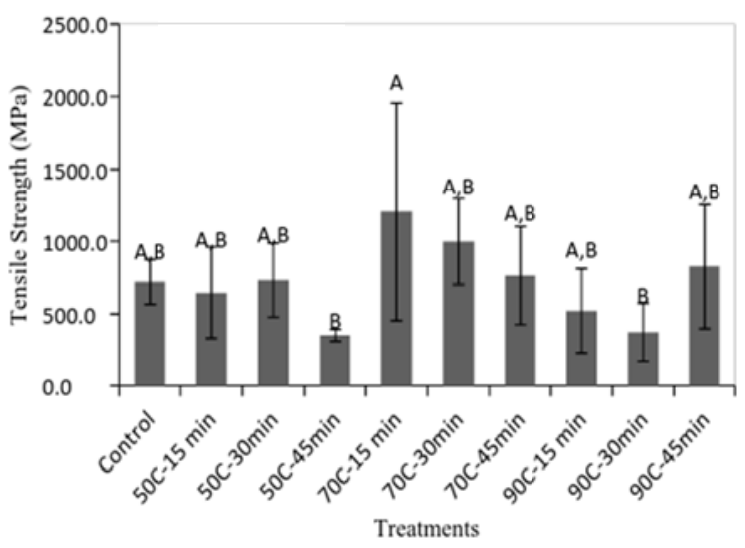

Figure 1. Tensile strength of hot water treated PALF

The minimum tensile strength was recorded with the PALF treated at $50^{\circ} \mathrm{C}$ for $45 \mathrm{~min}$, which was 353.1 $41.51 \mathrm{MPa}$. Therefore the tensile strength of hot water treated PALF was within the permissible limit for industrial application. The means were compared using Tukey-Kramer HSD test (JMP Software, SAS Inc., North Carolina USA). According to Tukey-Kramer test, the PALF pre-treated at $70^{\circ} \mathrm{C}$ for 15 min showed a significant difference with the PALF pre-treated at $90^{\circ} \mathrm{C}$ for 30 min and $50^{\circ} \mathrm{C}$ for $45 \mathrm{~min}$. All the other treatments didn't show any significant difference in their tensile strengths. The tensile strength of PALF did not show any particular trend with respect to the treatments, which is because of the diverse nature of biomaterials [17]. With respect to tensile strength, the hot water pretreatment for the decortication of PALF was acceptable within the range of $50-90^{\circ} \mathrm{C}$, with the treatment time from $15-45 \mathrm{~min}$. 


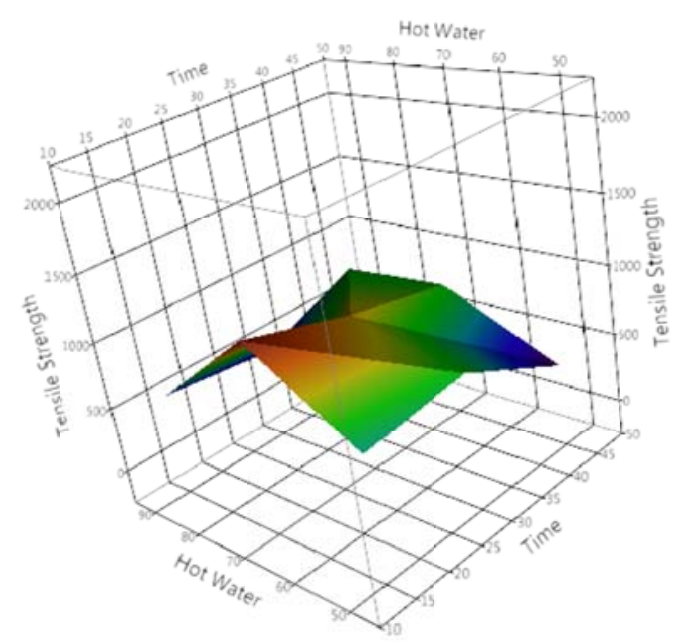

Figure 2. Surface plot of temperature of the hot water, treatment time (min) and tensile sttrength (MPa) of PALF hot water pre-treatment

As can be observed in Figure 2 which plotted the individual relationship annong the factors, the tensile strength of PALF was increased from 50 to $70^{\circ} \mathrm{C}$ and then it decreased from 70 to $90^{\circ} \mathrm{C}$. Initially, the PALF showed an increase in its tensile strength with respect to an increase in alkali concentrations and treatment times, which was because of the removal of weaker fibers and impurities (lignin, hemicellulose and pectin). In hot water treatment, the tensile strength of P'ALF was found to be decreasing because of the fiber degradation at higher temperatures $[18,19]$.

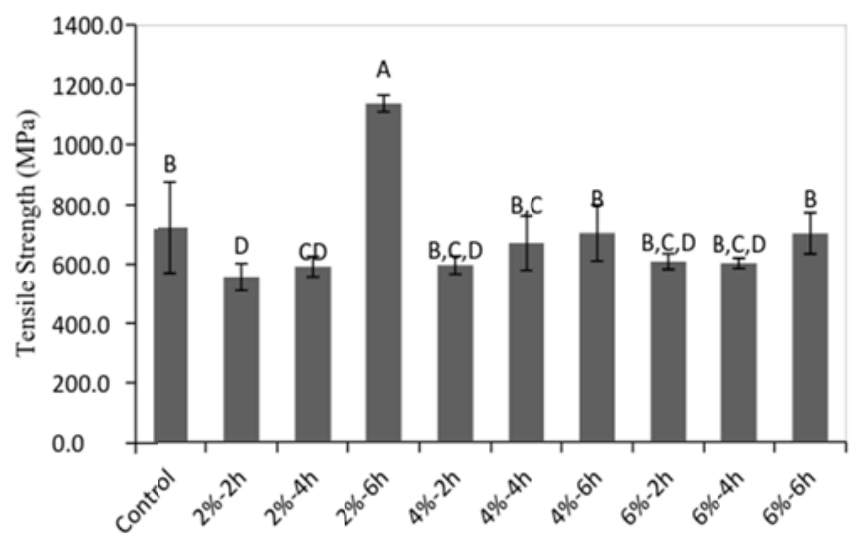

Figure 3. Tensile strength of alkali treated PALF

The tensile strength of alkali pre-treated pineapple leaf fibers is as shown in Figure 3. The values ranged between 1137.2 $\mathrm{MPa}$ (PALF treated with 2\% alkali solution for $6 \mathrm{~h}$ ) and $553.5 \mathrm{MPa}$ (PALF treated with $2 \%$ alkali solution for $2 \mathrm{~h}$ ). With respect to Tukey-Kramer HSD test, the PALF treated with $2 \%$ alkali solution for $6 \mathrm{~h}$ showed a significant difference in its tensile strength value with others. The control sample and PALF treated with $6 \%$ alkali solution for 6 hours showed a significant difference with the other PALF samples. The tensile strength of the alkali pre-treated PALF was ranged within the acceptable range for various industrial applications. 


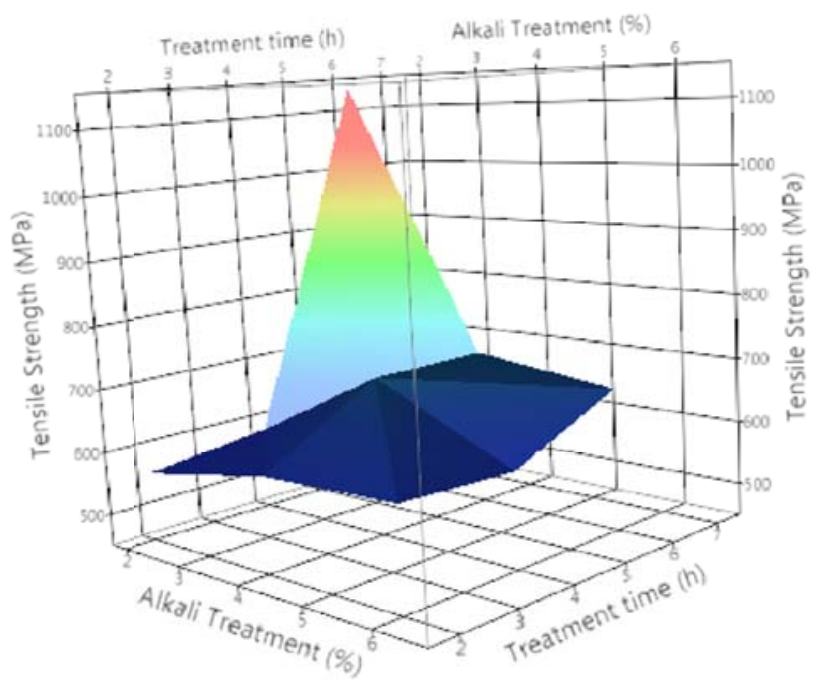

Figure 4. Surface plot of alkali solution (\%), treatment time (min) and tensile strength (MPa) of PALF alkali pretreatment

Figure 4 shows the surface plot of the tensile strength of PALF with various alkali pre-treatment conditions. Except for $2 \%$ alkali- treatment, there was no significant increase in tensile strength with respect to the time of treatment. For instance, for a $2 \mathrm{~h}$ pre-treated PALF, the ellongation increases as the tensile strength increase which can be said for most. However, beyond a percentage elongation of $4 \%$ for a $4 \mathrm{~h}$ pre-treated PALF, the tensile strength begins to drop and that goes as well with an increase in treatment time. The reason is that PALF treated at longer time will have its impurities removed and thus its percentage elongation dropped as its tensile strength dropped.

\subsubsection{Elongation}

The maximum percentage of elongation of PALF with various hot water pre-treatments is shown in Figure 5. The maximum percentage of elongation was found to be for control PALF samples, followed by PALF treated at $50^{\circ} \mathrm{C}$ for $15 \mathrm{~min}$. The least percentage of elongation was found to be for PALF treated at $70^{\circ} \mathrm{C}$ for $15 \mathrm{~min}$. As observed from Figure 5, the PALF treated at higher temperature showed a significantly low elongation, which is because of the degradation and shrinkage of components (lignin, hemicellulose) of fiber at higher temperature which resulted in breaking of fiber at lower force [20].

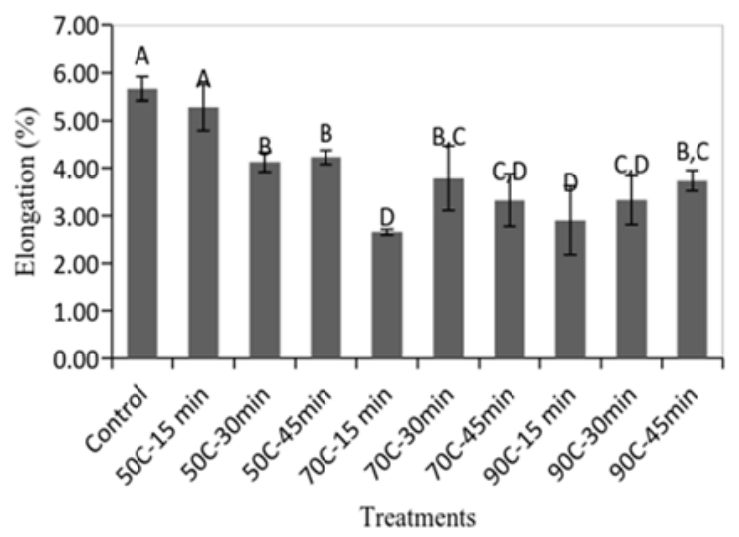

Figure 5. The elongation (\%) of hot water treated PALF at maximum applied force 


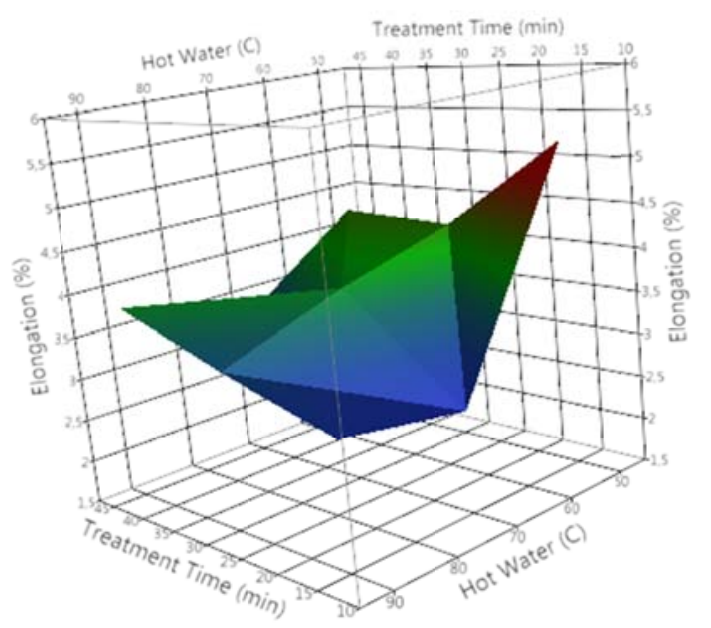

Figure 6. Surface plot of hot water temperature $\left({ }^{\circ} \mathrm{C}\right)$, treatment time $(\mathrm{min})$ and elongation $(\%)$ of PALF hot water pre-treatment

According to Figure 6 which plotted the individual relationship among the factors of temperature $\left({ }^{\circ} \mathrm{C}\right)$, treatment time (min), and elongation (\%), the elongation of PALF was increased from 50 to $70^{\circ} \mathrm{C}$ and then increased tremendously from 70 to $90^{\circ} \mathrm{C}$ for PALF 15 min pre-treated. PALF 45 min pre-treated presents the lower increase in percentage elongation. The reason for the initial increase in elongation is the same as mentioned in the analysis of figure 2. With higher temperature the ligmin and cellulose tend to breakdown at a molecular level and that reduce the tensile strength that can be applied to the fiber therefore reducing its elongation capacity [18, 19].

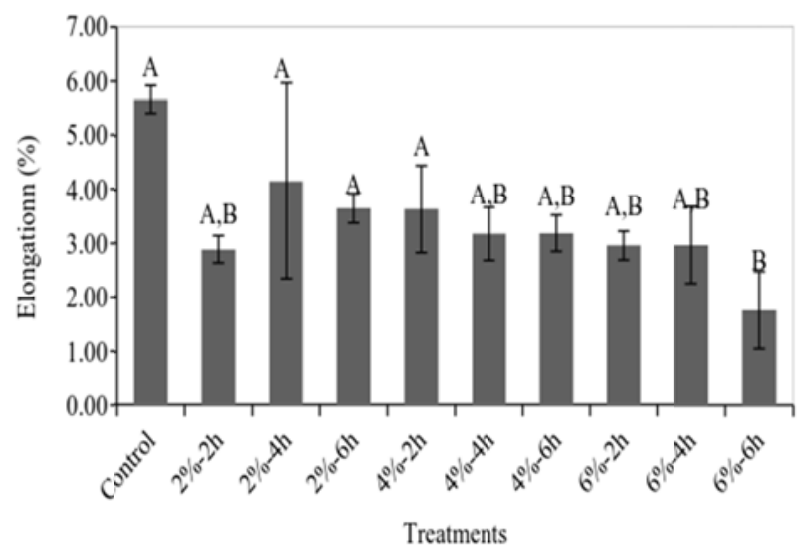

Figure 7. The elongation (\%) of alkali treated PALF at maximum applied force

The maximum percentage elongation of alkali pre-treated PALF is shown in Figure 7. The maximum percentage of elongation was found to be for control PALF samples, followed by PALF treated at $2 \%$ $\mathrm{NaOH}$ for 4 hours and 6 hours followed by the PALF treated at $4 \% \mathrm{NaOH}$ for $2 \mathrm{~h}$. The least percentage of elongation was found to be for PALF treated at $6 \% \mathrm{NaOH}$ for $6 \mathrm{~h}$. It happens that the PALF treated at $6 \% \mathrm{NaOH}$ for $6 \mathrm{~h}$ present lower percentage elongation because it breaks with a lower tensile strength applied to it due to the fact that the degradation and washing of lignin and hemicellulose render the PALF thin and breakable at lower applied force [20]. 


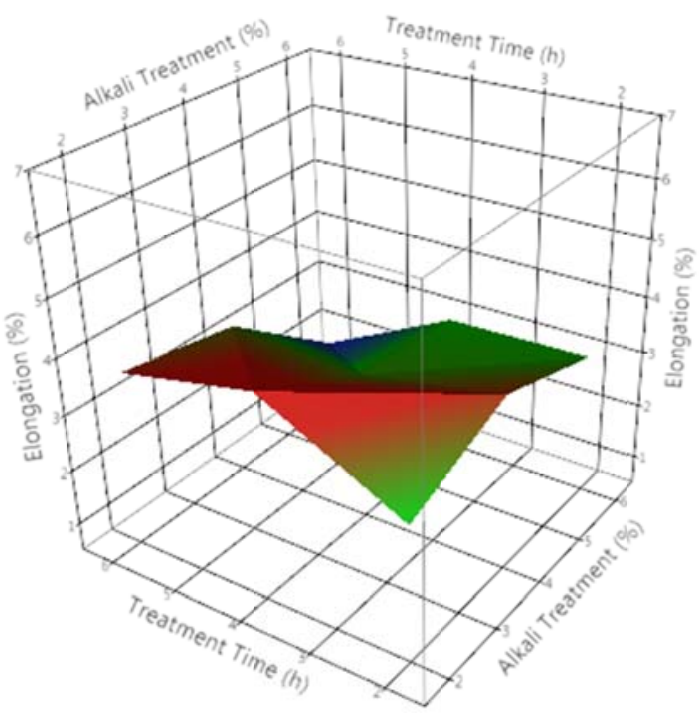

Figure 8. Surface plot of alkali (\%), treatment time (min) and elongation (\%) of PALF alkali pre-treatment

Figure 8 represents the individual relationship among the factors of alkalinity $(\% \mathrm{NaOH})$, treatment time (min), and elongation (\%), the elongation of PALF was increased from $2 \mathrm{~h}$ to $4 \mathrm{~h}$ and then decreased from 4 to $6 \mathrm{~h}$. The initial increase in percentage elongation is due to the fact that alkali solution acted as a purifier for PALF thus removing the lignin, hemicellulose, pectin and rendering the PALF easily breakable, thus percentage elongation is lowered [18, 19].

\subsection{Color Analysis}

\subsubsection{Hot Water Treated PALF}

The change of color of hot water treated PALF when compared with the control sample is as shown in Figure 9.

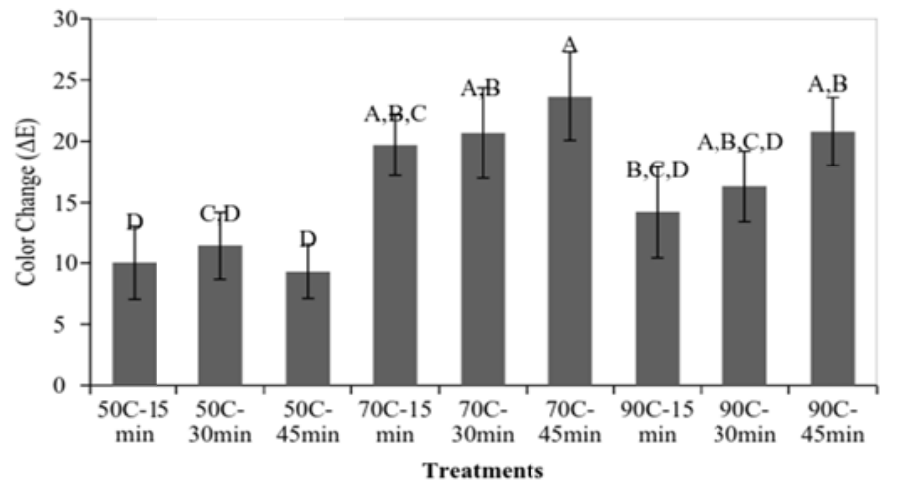

Figure 9. The color change $(\Delta \mathrm{E})$ of hot water treated PALF

The color change was found to be maximum for PALF treated at $70^{\circ} \mathrm{C}$ for 45 min which significantly differs from PALF treated at $50^{\circ} \mathrm{C}$. According to Figure 9, all the PALF treated at $70^{\circ} \mathrm{C}$ showed significantly higher color change, along with $90^{\circ} \mathrm{C}-30 \mathrm{~min}$ and $90^{\circ} \mathrm{C} 45 \mathrm{~min}$. From Table 1 , the PALF treated at $70^{\circ} \mathrm{C}$ showed high $\mathrm{L}^{*}$ values of 57.0556 .68 and 60.93 . Since $\mathrm{L}^{*}$ demonstrates whiteness/brightness of the PALF, the hot water treated PALF samples at $70^{\circ} \mathrm{C}$ showed high whiteness/brightness with respect to other PALF including control samples. Since whiteness is a crucial factor as per the industrial acceptability, the PALF treated at $70^{\circ} \mathrm{C}$ for 45 min showed maximum acceptability [7]. 


\subsubsection{Alkali-Treated PALF}

The change of color of hot water treated PALF when compared with the control sample is as shown in Figure 9. The color change was found to be maximum for PALF treated at $2 \% \mathrm{NaOH}$ for $2 \mathrm{~h}$ followed by pre-treated PALF of $6 \% \mathrm{NaOH}$ for $2 \mathrm{~h}$ and $4 \% \mathrm{NaOH}$ for $2 \mathrm{~h}$. According to figure 10 , the three anterior pre-treated PALF mentioned have presented higher color change and the $6 \% \mathrm{NaOH}$ pre-treated PALF showed higher color change.

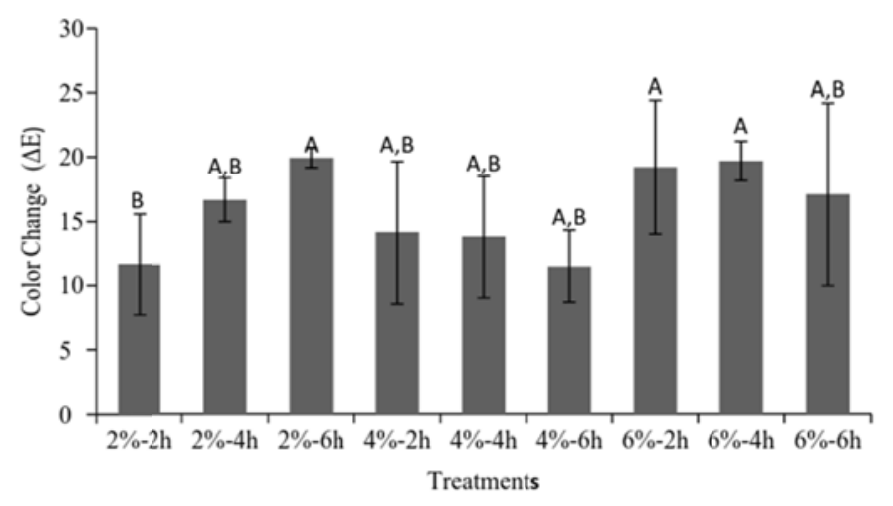

Figure 10. The color change $(\Delta \mathrm{E})$ of alkali pre-treated PALF

From Table 1, the PALF treated at $90^{\circ} \mathrm{C}$ showed high $\mathrm{L}^{*}$ values of $56.06,56.13$ and 53.77 thus the PALF treated at $90^{\circ} \mathrm{C}$ showed more whiteness/brightness with respect to other PALFs including the control sample. There the PALF treated at $90^{\circ} \mathrm{C}$ showed maximum acceptability in the textile industrial market [7].

Table 1. $\mathrm{L}^{*}, \mathrm{a}^{*}, \mathrm{~b}^{*}$ values of hot water and alkali pre-treated PALF

\begin{tabular}{c|c|c|c|c|c|c|c}
\hline & \multicolumn{2}{|l|}{ Hot Water Treatment } & \multicolumn{3}{l|}{ Alkali Treatment } & \\
\hline Treatments & $\mathrm{L}^{*}$ & $\mathrm{a}^{*}$ & $\mathrm{~b}^{*}$ & Treatments & $\mathrm{L}^{*}$ & $\mathrm{a}^{*}$ & $\mathrm{~b}^{*}$ \\
\hline Control & $38.94 \pm 2.11$ & $-0,31$ & $23.36 \pm 4.91$ & Control & $38.93 \pm 2.11$ & $-0,31$ & $23,36 \pm 4.91$ \\
\hline $50^{\circ} \mathrm{C}-15 \mathrm{~min}$ & $43.52 \pm 2.07$ & $3.47 \pm 3.37$ & $22.69 \pm 0.59$ & $2 \%-2 \mathrm{~h}$ & $48.19 \pm 3.24$ & $-2,06$ & $22.28 \pm 2.11$ \\
\hline $50^{\circ} \mathrm{C}-30 \mathrm{~min}$ & $48.27 \pm 1.49$ & $1.14 \pm 0.73$ & $24.79 \pm 1.69$ & $2 \%-4 \mathrm{~h}$ & $53.21 \pm 2.75$ & $-4,28$ & $20.4 \pm 3.06$ \\
\hline $50^{\circ} \mathrm{C}-45 \min$ & $45.7 \pm 2.59$ & $2.92 \pm 1.55$ & $25 \pm 3.57$ & $2 \%-6 \mathrm{~h}$ & $57.24 \pm 1.97$ & $-1,82$ & $18.62 \pm 1.93$ \\
\hline $70^{\circ} \mathrm{C}-15 \min$ & $57.05 \pm 3.52$ & $-0,85$ & $25.17 \pm 0.05$ & $4 \%-2 \mathrm{~h}$ & $51.59 \pm 0.89$ & $-1,28$ & $24.85 \pm 2.69$ \\
\hline $70^{\circ} \mathrm{C}-30 \min$ & $56.68 \pm 0.92$ & $1.3 \pm 1.34$ & $30.49 \pm 2.38$ & $4 \%-4 \mathrm{~h}$ & $51.36 \pm 3.04$ & $-0,28$ & $21.91 \pm 1.55$ \\
\hline $70^{\circ} \mathrm{C}-45 \min$ & $60.93 \pm 5.54$ & $0.11 \pm 1.26$ & $26.4 \pm 3.04$ & $4 \%-6 \mathrm{~h}$ & $47.49 \pm 2.73$ & $-2,68$ & $20.17 \pm 1.98$ \\
\hline $90^{\circ} \mathrm{C}-15 \min$ & $49.26 \pm 4.7$ & $2.85 \pm 1.87$ & $22.7 \pm 5.02$ & $6 \%-2 \mathrm{~h}$ & $56.06 \pm 4.04$ & $-2,39$ & $18.72 \pm 2.33$ \\
\hline $90^{\circ} \mathrm{C}-30 \min$ & $52.84 \pm 2.02$ & $0.61 \pm 0.62$ & $27.34 \pm 1.22$ & $6 \%-4 \mathrm{~h}$ & $56.13 \pm 2.83$ & $-3,93$ & $26.09 \pm 3.21$ \\
\hline $90^{\circ} \mathrm{C}-45 \min$ & $58.36 \pm 2.85$ & $-3,05$ & $23.93 \pm 1.65$ & $6 \%-6 \mathrm{~h}$ & $53.77 \pm 0.62$ & $-1,37$ & $20.22 \pm 1.13$ \\
\hline
\end{tabular}

Table 1 shows $L^{*}, a^{*}, b^{*}$ values of Hot Water and Alkali Pre-Treated PALF which demonstrate the whiteness/brightness of PALF. A vertical analysis showed the hot water pre-treatment PALF at $70^{\circ} \mathrm{C}$ presented higher whiteness/brightness and the alkali pre-treatment PALF at $6 \% \mathrm{NaOH}$ presented mayor whiteness/brightness thus more accepted to the textile industry. A horizontal analysis showed that for PALF pre-treated with alkali showed in general mayor whiteness/brightness than most of PALF pretreated with hot water even though the PALF pre-treated at $70^{\circ} \mathrm{C}$ for 45 min showed the highest whiteness/brightness of all treatments. 


\section{Conclusion}

The effect of pre-treatment on the extraction of PALF was studied by comparing the physical and surface qualities of fiber obtained from hot water and alkali treatments. Hot water pre- treatment was conducted at 50,70 , and $90^{\circ} \mathrm{C}$, then PALF was extracted and the results were analyzed and compared with the properties of PALF pre-treated with $\mathrm{NaOH}$ concentrations of 2,4 , and $6 \%$. The two treatments show similar results and no significance difference in terms of tensile strength and percentage elongation. Hot water treated PALF showed higher values of color change $(\Delta E)$, with higher $L^{*}$ values which represent brightness/whiteness. The surface properties of PALF analyzed from the treatments showed that the alkali treated PALF had a better surface properties and the best surface properties were obtained with $6 \%$ alkali treated PALF.

\section{References}

1. Van Tran, A. "Chemical analysis and pulping study of pineapple crown leaves". Industrial crops and products, Vol. 24, no. 1, pp. 66-74, 2006

2. Uma Devi, L., Bhagawan, S.S. and Thomas, S. "Mechanical Properties of Pineapple Leaf Fiber-Reinforced Polyester Composites". Journal of Applied Polymer Science. Vol. 64, pp. 1739-1748, 1997.

3. Dey, S. K., Nag, D., \& Das, P. K. "New dimensions of pineapple leaf fibre-an agrowaste for textile application". New technologies for rural development having potential of commercialisation. Allied Publishers Private Limited, Delhi, pp. 115-127, 2009

4. Debnath, S. "Pineapple Leaf Fibre-A Sustainable Luxury and Industrial Textiles", In Handbook of Sustainable Luxury Textiles and Fashion, pp. 35-49, 2016.

5. Kannojiya, R., Gaurav, K., Ranjan, R., Tiyer, N. K., \& Pandey, K. M. "Extraction of pineapple fibres for making commercial products", Journal of Environmental Research and Development, vol. 7, no. 4, pp. 1385, 2013.

6. Saha, S. C., Das, B. K., Ray, P. K., Pandey, S. N., \& Goswami, K. "Some physical properties of pineapple leaf fiber (PALF) influencing its textile behavior", Journal of applied polymer science, vol. 50, no. 3, pp. 555-556, 1993.

7. Nair, G. R., Rho, D., Yaylayan, V., \& Raghavan, V. "Microwave assisted retting-A novel method of processing of flax stems", Biosystems engineering, Vol. 116, no. 4, pp. 427-435, 2013.

8. Py, Claude \& Lacoeuilhe, Jean Joseph \& Teisson, Claude "The pineapple : cultivation and uses" Maisonneuve \& Larose, Paris, 1987

9. Bhattacharyya, P. "Extracting pineapple leaf fibre", Appropriate technology, Vol. 24, no. 4, pp. 27, 1998.

10.Cherian, B. M., Leão, A. L., de Souza, S. F., Costa, L. M. M., de Olyveira, G. M., Kottaisamy, M., \& Thomas, S. "Cellulose nanocomposites with nanofibres isolated from pineapple leaf fibers for medical applications", Carbohydrate Polymers, Vol. 86, no. 4, pp. 1790-1798, 2011.

11.Mohamed, A. R., Sapuan, S. M., Shahjahan, M., \& Khalina, A. "Characterization of pineapple leaf fibers from selected Malaysian cultivars", Journal of Food, Agriculture \& Environment, Vol. 7, no. 1, pp. 235-240, 2009.

12.Bengtsson, M., Gatenholm, P., \& Oksman, K. "The effect of crosslinking on the properties of polyethylene/wood flour composites", Composites Science and Technology, Vol. 65, no. 10, pp. 1468-1479, 2005.

13.George, J., Sreekala, M. S., \& Thomas, S. "A review on interface modification and characterization of natural fiber reinforced plastic composites" Polymer Engineering \& Science, Vol. 41 no. 9, pp. 1471-1485, 2001.

14.Banik, S., Nag, D., \& Debnath, S. Utilization of pineapple leaf agro-waste for extraction of fibre and the residual biomass for vermicomposting. Indian Journal of Fibre and Textile Research, Vol. 36, no. 2, 2011.

15.Yuan, X., Mak, A. F., Kwok, K. W., Yung, B. K., \& Yao, K. "Characterization of poly (L-lactic acid) fibers produced by melt spinning", Journal of Applied Polymer Science, Vol. 81, no. 1, pp. 251-260, 2001.

16.Teles, M. C. A., Glória, G. O., Altoé, G. R., Amoy Netto, P., Margem, F. M., Braga, F. O., \& Monteiro, S. N. "Evaluation of the Diameter Influence on the Tensile Strength of Pineapple Leaf Fibers (PALF) by Weibull Method", Materials Research, (AHEAD), 2015.

17.Saheb, D. N., \& Jog, J. P. "Natural fiber polymer composites: a review", Advances in polymer technology, vol. 18, no. 4, pp. 351-363, 1999 
18.Azwa, Z. N., \& Yousif, B. F. "Thermal degredation study of kenaf fibre/epoxy composites using thermo gravimetric analysis" InProceedings of the 3rd Malaysian Postgraduate Conference (MPC 2013), pp. 256-264, 2013.

19.Ku, H., Wang, H., Pattarachaiyakoop, N., \& Trada, M. "A review on the tensile properties of natural fiber reinforced polymer composites", Composites Part B: Engineering, Vol. 42, no. 4, pp. 856-873, 2011.

20.Dhakal, H. N., Zhang, Z. Y., \& Richardson, M. O. W. "Effect of water absorption on the mechanical properties of hemp fibre reinforced unsaturated polyester composites", Composites science and technology, Vol. 67, no. 7, pp. 1674-1683, 2007. 